\title{
MEASUREMENT OF GROWTH AND EFFICIENCY IN ARITHMETIC
}

\author{
S. A. COURTIS \\ Home and Day School, Detroit
}

The following pages describe in some detail the efforts of the writer to establish a standard from which to measure the success or failure of a reorganization of the mathematics courses in his charge, and to trace the development of ability in arithmetic from the primary grades through the high school. Such tests, repeated at frequent intervals, would, it seems to the writer, make standardization of yearly work possible, would show exactly the place, manner, and amount of development of any particular ability, and would give a rational basis for the estimation of the influence exerted by any method, material, or teacher.

The direct inspiration of the experiment was No. I9, of the Teacher's College Series, Contributions to Education, published by Columbia University and entitled, "Arithmetical Abilities; Some Factors Determining Them," by Dr. C. W. Stone. For the benefit of those who are not familiar with that publication, a brief summary of one or two of the essential points is given.

Dr. Stone visited and personally gave, under conditions as nearly identical as possible, two tests, one in fundamentals and one in reasoning, to 3,000 sixth-grade children in 26 school systems in 6 different states from Indiana to New York. The tests are given in full on pp. 61 and 64 although the method of scoring there found is not that used by Dr. Stone. Dr. Stone made a careful examination of the course of study, time allowance, character of supervision, etc., of each school, but with these we shall not be concerned. The scores made by the different schools show that, taking the efficiency of the school making the highest score in fundamentals as roo per cent., the efficiency represented by the median score was 76 per cent., that of the lowest score 45 per cent. In reasoning the results were even 
worse, the median score representing an efficiency of 60 per cent., the lowest score an efficiency of 39 per cent. In other words, for most schools the work that is now done in four years could be accomplished in three for fundamentals, and two and a half for reasoning, if more efficient methods were adopted. If the time element is considered, the results are much worse; for the percentage of the school time given to arithmetic was found to vary from 7 to 23 per cent., and high ability appeared more commonly with the small rather than with the great expenditure of time. It was not possible to say what are efficient methods; for there was wide variation even among schools using essentially the same method and the same general course of study.

Moved by the laudable ambition of finding the place of the school with which he is connected among the 26 school systems, the writer undertook to give Dr. Stone's tests to the sixth grade. A little consideration made it evident that parts of the tests were within the abilities of third-grade children, while the length of the tests would provide work to keep even the seniors busy during the whole of the allotted time. Here then was a means of testing the development of the arithmetical abilities throughout the school, and with the consent and co-operation of the principal, Dr. Stone's tests were given under as nearly identical conditions as possible to every grade in the school from the third to the thirteenth, or last year in the high school, inclusive. The tests thus became a measure, not only of the ability gained during the eight years of arithmetic, but also of what happens to that ability as the child undergoes the training of her high-school mathematics and science. Before considering the test itself, however, the reader needs to know something of the school and of the conditions under which the ability tested was gained.

The school in question is a private school for girls. The total enrolment last year (I908-9) was 3I7, making the average number of girls in a grade 23. Any class is sectioned as soon as its membership rises above twelve, and further provision is made, through a system of "interviews" for a careful, yet legitimate, assistance of the weaker menibers. The method of instruction is thus distinctly "individuaisstic." Girls are received in the 
kindergarten, carried through eight grades in the elementary school, five in the high school, and are then admitted to the leading colleges without examination. Approximately half the girls take the college course. This past year, for instance, there were 24 graduates of the school enrolled in Vassar College alone.

The instruction in arithmetic, as in other subjects, has during the last ten years undergone radical changes. Complaints of lack of ability in arithmetic shown in the laboratory work in science has lead to correlation between the two subjects, and the gradual adoption of laboratory methods in arithmetic itself, while many laboratory exercises and methods are making their way into the algebra and geometry classes of the high school. Two years ago the two subjects, science and mathematics, were made one department, under the control of one head, and a strict, objective laboratory system of instruction adopted throughout. It will be noted that the past few years have been a transition period and the conditions of teaching have been unsettled. The changes may be described as an adoption of the cyclic-objective method in place of the topic-drill method. At the present time grades $\mathrm{I}-4$ have had a fair amount of laboratory training, grades 5-7 a small amount for one year, grade 8 a large amount for one year, grades 9 and ro a less amount for a year, and grades I I, I2, I3 none except through their science work. Part of grade I3, however, reviewed algebra and geometry during the year, following the general plan of the new method, but with few laboratory exercises.

The general method of giving the tests was that followed by Dr. Stone. The examples were typewritten and the paper fastened to a sheet of blank paper by means of a clip so that the typew riting was on the inside. These papers were distributed in the assembly rooms of the school, the whole of each division of the school being tested at one time. The girls were told to write their names and grades on the blank sheet, but not to look at the examples until given a signal. It was explained that the purpose was to test the ability of the whole school in arithmetic, not the individual, but that each must do her best for the honor of her class. Then the signal was given and at the end of the allotted 
time, twelve minutes for fundamentals, fifteen for reasoning, another signal was given and the papers collected. The tests were given on successive days at about the middle of the morning near the close of the year. The children did not know the tests were to be given, nor how much time they were to have.

The test in fundamentals and the score in points for each example (see below) was as follows:

\section{ARITHMETIC TEST}

Work as many of these problems as you have time for: work them in order as numbered.

I. Add :

I9 additions.

260

$504 \mathrm{I}$

I 543

2. Multiply 3265 by 20 .

3. Divide 3328 by 64 .

4. Add:
5. Multiply 768 by 604 .

6. Divide 1918962 by 543 .

7. Add:

4695

872

7948

7499

6786

567

858

9447
2 additions, 5 multiplications.

2 additions, 3 subtractions, 4 multiplications, 2 divisions.

20 additions.

7 additions, 7 multiplications.

6 additions, Io subtractions, I2 multiplications, 4 divisions.

28 additions.

8. Multiply 976 by 87 .
8 additions, 6 multiplications. 
9. Divide 2782542 by 679 .

Io. Multiply 5489 by 9876 .

II. Divide 509994I by 749 .

I2. Multiply 876 by 79 .

13. Divide 62693256 by 859 .

I4. Multiply 96879 by 896 .
6 additions, 7 subtractions, 9 multiplications, 4 divisions.

28 additions, 16 multiplications.

6 additions, 7 subtractions, 9 multiplications, 4 divisions.

9 additions, 6 multiplications.

Io additions, I3 subtractions, I5 multiplications, 5 divisions.

28 additions, 15 multiplications.

It will be noticed that the ability tested is that involved in the handling of abstract numbers in addition, multiplication, division, and (incidentally in division) subtraction. Speed and accuracy in such work are certainly fundamental in all mathematics, and whatever else the course in arithmetic may give, it must produce such ability. Criticism of the test itself will be made later.

The papers were scored in two different ways. By the first method, called hereafter "by examples," each example attempted gave a count of one. When the correct answer was obtained the example was scored as one right. If the answer was wrong for any reason it was not scored in the second count. For instance an example copied wrong but worked correctly was counted one attempted, but not one right, as was also example 6, worked correctly but marked example 4. A record was kept by name and grade of the examples attempted (Attempts), and the examples right (Rights). The individual scores were analyzed into examples in addition, multiplication, and division. Here a record was made, for each example wrong, of the character of the mistake, whether in addition, subtraction, multiplication, division, or copying or carrying. The total for each grade was found from the individual records.

The second method of scoring was "by points." It grew out of a desire to analyze the papers and mistakes on a basis of mental effort involved, but proved rather unwieldy and unsatisfactory. It was found that no two persons would use quite the same judgment in analyzing a paper, and that it was difficult for even a single individual to follow a consistent system. The scores and the results are given, however, as with a suitable test, such a system of scoring would be of value. In the main, the 
results obtained even in this test are believed to be correct within two or three percentages, all the scoring being done finally by one person. For several grades the scores were marked separately by two individuals and the results compared. For all the grades the different points scored made a certain checking of the results necessary and this also contributed to the general accuracy.

In detail the scores by points as given were determined as follows :

The first example given above was

Add : 2375

In solving this example the child in the third grade 4052 goes through four additions for the first column; 6354 $3+\mathrm{I}=4 ; 4+4=8 ; 8+2=\mathrm{IO} ; \mathrm{IO}+5=\mathrm{I} 5:$ six addi260 tions for the second column; I (carried) $+4=5$; $504 \mathrm{I}$ $5+4=9 ; \quad 9+6=$ I $5 ; \quad$ I $5+5=20 ; \quad 20+5=25 ;$ I 543 $25+7=32$ : four for the third column, and five for the last column, a total of I9. If the answer to example I were given as 19,685 (correct answer, I9,625), the child was given a score of 19 points in addition attempted, I3 points (the total I9, less the additions in the second column, 6), right. In multiplication and division the attempt was made to separate the incidental additions and subtractions from the multiplications and divisions. For instance, in example 3,64$) 3328\left(5^{2}\right.$ the steps are $33 \div 6=5$, one point in division; $5 \times 4=320$ 20 , one point in multiplication; $5 \times 6=30$, one point in multiplication, $30+2$ (carried) $=32$, one point in addition; o from $2=2$, one point in subtraction: 2 from $3=\mathrm{I}$, one point in subtraction, and so on, the total score for a correct answer being, as given, 2 additions, 3 subtractions, + multiplications, 2 divisions. In some respects the scores were arbitrary assignments of value, as when the recognition of I 28 as equal to I 28 was counted as one point in subtraction, but in all such cases the same scores were used throughout and affected all alike. In most cases it was comparatively easy to form an opinion as to whether a mistake was in the actual multiplying and dividing or in the carrying. For instance, when $5 \times 543$ was given as 2,6 I $_{5}$, the multiplication $5 \times 5=25$ was counted as correct and the mistake that of carry- 
ing $I$ in place of 2 from the previous $2 \mathrm{I}$. This was counted as a mistake in addition. If $6 \times 768$ was given as 5,208 , the four from the previous 40 was probably carried correctly and the mistake one of multiplication, $6 \times 7$ being called 48 . In other cases the character of the mistake was not so plain and the classification a mere guess. Most mistakes in multiplication, however, seem to consist in the substitution of one part of the multiplication table for another. This and other similar experiences formed a basis from which judgments could be made. After all the papers had been scored as above, they were gone over a second time and the attempt was made to separate mistakes in carrying and copying from all others. These were called mistakes due to faulty attention (A).

As to whether it is worth while, or not, to give the time needed for such careful scrutiny of each result, there will undoubtedly be two opinions. The writer wished to know, however, whether the children performed the different operations with equal ease, and in case of failure, to what the failure was due. It is manifestly useless to drill children on the multiplication tables for instance, if failure in multiplication is due to inability to carry, and it is equally useless to attempt elaborate examples in multiplication and division if the fundamental combinations are imperfectly mastered. The writer personally considers his time well spent, but the results must speak for themselves.

The test for reasoning, and scores by points, was as follows:

\section{ARITHMETIC TEST}

Solve as many of the following problems as you have time for; work them in order as numbered.

I. If you buy two tablets at 7 cents each and a book for 65 cents, how much change should you receive from a two-dollar bill?

SCORE

$2-\left[\left(2 \times_{7}\right)+65\right]$. One point each for addition, subtraction, and multiplication.

2. John sold 4 Saturday Evening Posts at 5 cents each. He kept $1 / 2$ the money and with the other half he bought Sunday papers at 2 cents each. How many did he buy? 
SCORE

$4+5=20.20 \div 2=$ 10. I0 $\div 2=5$. One point for multiplication and two for division.

3. If James had 4 times as much money as George, he would have \$I6. How much money has George?

SCORE

I6 $\div 4=4$. One point for division.

4. How many pencils can you buy for 50 cents at the rate of 2 for 5 cents?

SCORE

$50 \div 5=$ 10. Iо $\times 2=20$. One point for multiplication, one for division.

5. The uniforms for a baseball nine cost $\$ 2.50$ each. The shoes cost $\$ 2$ a pair. What was the total cost of the uniforms and shoes for the nine?

SCORE

$(9 \times 2.50)+(9 \times 2)$. One point for addition, two for multiplication.

6. In the schools of a certain city there are 2,200 pupils; $1 / 2$ are in the primary grades, $1 / 4$ in the grammar grades, $1 / 8$ in the high school, and the rest in the night school. How many pupils are there in the night school?

SCORE

$2,200 \div 2=$ I,IOO. $\quad 2,200 \div 4=550 . \quad 2,200 \div 8=275 . \quad(\mathrm{I}, \mathrm{IOO}+550+275)=\mathrm{I}, 925$. $2,200-I, 925=275$. One point for addition, one for subtraction, three for division.

7. If. $3^{\mathrm{I} / 2}$ tons of coal cost $\$ 2 \mathrm{I}$, what will $5^{\mathrm{T} / 2}$ tons cost?

SCORE

$5 \cdot 5(21 \div 3.5)$. One point for multiplication, one for division.

8. A newsdealer bought some magazines for $\$ \mathrm{I}$. He sold them for $\$ 1.20$, gaining 5 cents on each magazine. How many magazines were there?

SCORE

$\mathrm{I} .20-\mathrm{I}=.20 \quad 20 \div 5=4$. One point for subtraction, one for division.

9. A girl spent $1 / 8$ of her money for carefare, and three times as much for clothes. Half of what she had left was 80 cents. How much money did she have at first?

SCORE

$\mathrm{I} / 8+3 / 8=4 / 8 . \quad \mathrm{I}-4 / 8=4 / 8 . \quad 4 / 8 \div 2=\mathrm{I} / 4 . \quad 80 \times 4=3.20 . \quad$ One point each for addition, subtraction, division, and two for multiplication. 
Io. Two girls receive $\$ 2.10$ for making button-holes. One makes 42, the other 28. How shall they divide the money?

SCORE

$42+28=70 . \quad 2.10 \div 70=.03 . \quad .03 \times 42 . \quad .03 \times 28$. One point each for addition and division, two for multiplication.

II. Mr. Brown paid $1 / 3$ the cost of a building; Mr. Johnson paid $1 / 2$ the cost. Mr. Johnson received $\$ 500$ more annual rent than $\mathrm{Mr}$. Brown. How much did each receive?

SCORE

$\mathrm{I} / 2-\mathrm{I} / 3=\mathrm{I} / 6 . \quad 500 \times 2 . \quad 500 \times 3$. One point for subtraction, two for multiplication.

12. A freight train left Albany for New York at 6 o'clock. An express left on the same track at 8 o'clock. It went at the rate of 40 miles an hour. At what time of day will it overtake the freight train if the freight train stops after it has gone 56 miles?

SCORE

$56 \div 40=\mathrm{r} .4 . \quad .4 \times 60=24 . \quad 8+\mathrm{r}: 24=9: 24$. One point each for addition, multiplication, and division.

This test was scored in the same two ways as the test on fundamentals, by examples, and by points. It will be noted from the scores given that a point stands for a single operation, a three-step problem counting three points. Individual and grade records were kept as before, each score being analyzed in the same way. Mistakes in the work were grouped in several classes. Using 8 cents instead of 7 cents in problem $I$ was called a mistake in attention (A) ; adding the difference of 65 and $I_{4}$ to 2.00 was called a total failure to comprehend the meaning of the example ( $\mathrm{T}$ ) ; using I block at 7 cents instead of 2 was called a mistake due to incomplete reading or appreciation of the English of the example-a mistake in attention (A) - such mistakes were not made by those who re-read the problem for the purpose of checking their work; problems correctly planned but containing mistakes in the work were said to be wrong because of mistakes in fundamentals $(F)$.

Besides these general records, a special record was kept of the number of examples in which there was an attempt to use either 
algebra or proportion. Approximately Ioo girls were in possession of enough algebraic skill to have enabled them to use simple equations had they cared to do so, although the fact that the paper was marked "Arithmetic Test" would have influenced many against the use of algebra. The neatness of the papers in both tests was also recorded in a rough way, two grades of neatness only being recognized-neat and untidy. Each paper was scored twice, however, and the doubtful ones near the dividing line gone over a third time. A paper was judged neat when its examples were arranged in a clear orderly fashion, properly numbered, and were without șerious blots or untidy marks and figures. A record was kept, also, of the perfect papers.

Before leaving the subject of scoring, it might be well to say again that many of the judgments upon which the scores were based were quite arbitrary in their nature, but that as nearly as possible the scoring was uniform throughout. In scoring by points allowance was made for individual variation by making up new scores of the same character where the individual had worked the problem in a longer or shorter way. That is, the scores by points represent scores upon the work that each individual put upon her paper, while the scores by examples show

TABLE I. PART I

Total Grade Scores

Actual results

" $\mathrm{F}$ " refers to fundamentals; " $\mathrm{R}$ " to reasoning

\begin{tabular}{|c|c|c|c|c|c|c|c|c|c|c|}
\hline \multirow{2}{*}{ Grade } & \multirow{2}{*}{\multicolumn{2}{|c|}{ No. IN Grade }} & \multicolumn{4}{|c|}{ Fundamentals } & \multicolumn{4}{|c|}{ REASONING } \\
\hline & & & \multicolumn{2}{|c|}{ Examples } & \multicolumn{2}{|c|}{ Points } & \multicolumn{2}{|c|}{ Examples } & \multicolumn{2}{|c|}{ Points } \\
\hline & $\mathrm{F}$ & $\mathrm{R}$ & At & $\mathrm{Rt}$ & At & $\mathrm{Rt}$ & At & Rt & At & $\mathrm{Rt}$ \\
\hline $3 \ldots \ldots$ & I 2 & I 2 & 23 & 3 & $44 \mathrm{I}$ & 237 & $4 \mathrm{I}$ & 20 & 97 & $7 \mathrm{I}$ \\
\hline 4. & I6 & I6 & 67 & 40 & 1005 & 891 & $8 \mathrm{I}$ & 57 & 203 & 175 \\
\hline 5. & 22 & 22 & r3o & $8 I$ & 2266 & 2080 & I86 & 94 & 538 & 383 \\
\hline & I3 & I 2 & 82 & 57 & I 585 & $\mathrm{I}_{4} 6_{3}$ & II 2 & 48 & 323 & 202 \\
\hline 7. & 23 & 22 & I60 & I 20 & 3062 & 2889 & I89 & I 23 & 555 & 455 \\
\hline 8 & $2 I$ & $2 I$ & I8I & I3I & 3634 & 3344 & 204 & 150 & 580 & 507 \\
\hline 9 . & r8 & I8 & I36 & IO8 & 2566 & 2474 & I 78 & I 29 & $5 \mathrm{I} 8$ & 439 \\
\hline Io. & $2 \mathrm{I}$ & $2 I$ & I89 & I39 & 3719 & 3566 & 217 & 167 & 632 & 559 \\
\hline II. & 23 & 25 & I 77 & I 44 & 3305 & 3155 & 255 & 218 & 768 & 710 \\
\hline I2.... & 33 & 29 & 264 & 203 & 5136 & 4840 & 279 & 223 & 828 & 740 \\
\hline \multirow[t]{2}{*}{ r $3 \ldots \ldots$} & I6 & I9 & I 47 & 122 & 3090 & 2998 & I98 & 160 & 599 & $53 \mathrm{I}$ \\
\hline & 218 & 217 & \multicolumn{8}{|c|}{ total number taking tests. } \\
\hline
\end{tabular}


TABLE I. PART 2

Total Grade Scores

Scores used for comparison of grade achievements. Computed on basis of uniform grades of 25 members each

" $\mathrm{F}$ " refers to fundamentals; " $\mathrm{R}$ " to reasoning

\begin{tabular}{|c|c|c|c|c|c|c|c|c|c|c|}
\hline \multirow{2}{*}{ GRADE } & \multirow{2}{*}{\multicolumn{2}{|c|}{ MUltiplier }} & \multicolumn{4}{|c|}{ FUNDAMENTALS } & \multicolumn{4}{|c|}{ Reasoning } \\
\hline & & & \multicolumn{2}{|c|}{ Examples } & \multicolumn{2}{|c|}{ Points } & \multicolumn{2}{|c|}{ Examples } & \multicolumn{2}{|c|}{ Points } \\
\hline 3. & $\begin{array}{c}F \\
2.08\end{array}$ & $\begin{array}{c}\mathrm{R} \\
2.08\end{array}$ & $\begin{array}{l}\text { At } \\
48\end{array}$ & ${ }_{6}^{\mathrm{Rt}}$ & $\begin{array}{l}\text { At } \\
9 \text { I } 7\end{array}$ & $\begin{array}{l}\text { Rt } \\
493\end{array}$ & $\begin{array}{l}\text { At } \\
85\end{array}$ & $\begin{array}{l}\mathrm{Rt} \\
42\end{array}$ & $\begin{array}{l}\mathrm{At} \\
2 \mathrm{O} 2\end{array}$ & $\begin{array}{l}\mathrm{Rt} \\
\mathrm{I} 48\end{array}$ \\
\hline $4 \ldots$ & I. $5^{6}$ & I. 56 & IO3 & 62 & I567 & 1390 & I 26 & 89 & 317 & 273 \\
\hline $5 \ldots \ldots$ & I. I4 & I. I4 & 148 & 93 & 2583 & 2371 & 212 & 107 & 6 I3 & 437 \\
\hline & I.93. & 2.08 & I $5^{8}$ & IIO & 3059 & 2824 & 233 & 100 & 672 & 420 \\
\hline $7 \ldots$ & I.09 & I. I4 & I74 & I3I & 3338 & 3149 & 215 & 140 & 633 & $5^{19}$ \\
\hline 8. & I. I9 & I. I9 & 216 & I 59 & 4324 & 3979 & 243 & I 78 & 690 & 603 \\
\hline 9 . & I $\cdot 39$ & I. 39 & I89 & 150 & 3566 & 3439 & 247 & 179 & 720 & 610 \\
\hline Io. & I. I9 & I. I4 & 225 & 165 & 4426 & 4243 & 247 & I90 & 720 & 637 \\
\hline I I. . & I.O9 & I. .00 & I93 & I 57 & 3602 & 3439 & 255 & $2 \mathrm{I} 8$ & 768 & 710 \\
\hline I $2 \ldots$ & .76 & .86 & 201 & I 55 & 3903 & 3678 & 240 & I92 & 712 & $6_{3} 6$ \\
\hline I $3 \ldots$ & I. 56 & I. $3^{2}$ & $23 I$ & IQI & 4820 & 4677 & 260 & $2 \mathrm{II}$ & 791 & 700 \\
\hline
\end{tabular}

how nearly the individual came to perfection. In each a mistake counted, but by points a careless inverting of two figures would deduct a single point, while by examples the paper lost the whole score for the example. Both scores should be considered in estimating the ability of a grade.

The results of the tests are given in the accompanying tables and graphs.

It is obviously unfair to compare the achievements of a grade with 33 members with that of a grade containing but 12 members. Accordingly these results have been equalized by computing what they would have been if the grade membership in each case had been 25 .

Graphically the results in Part 2 may be represented as shown in Plots I and 2.

The interpretation of the curves obtained is difficult in the absence of standards with which to compare the results. It must be remembered throughout this discussion that the inferences and conclusions made are from a single measurement only and are therefore tentative except as the writer is able to bring additional evidence to bear from his knowledge of the classes and conditions. It will need the tests of several years to eliminate 
differences due to variation in ability and class spirit alone. The factors determining ability are so many and their individual effects so little known that the results of the present test will
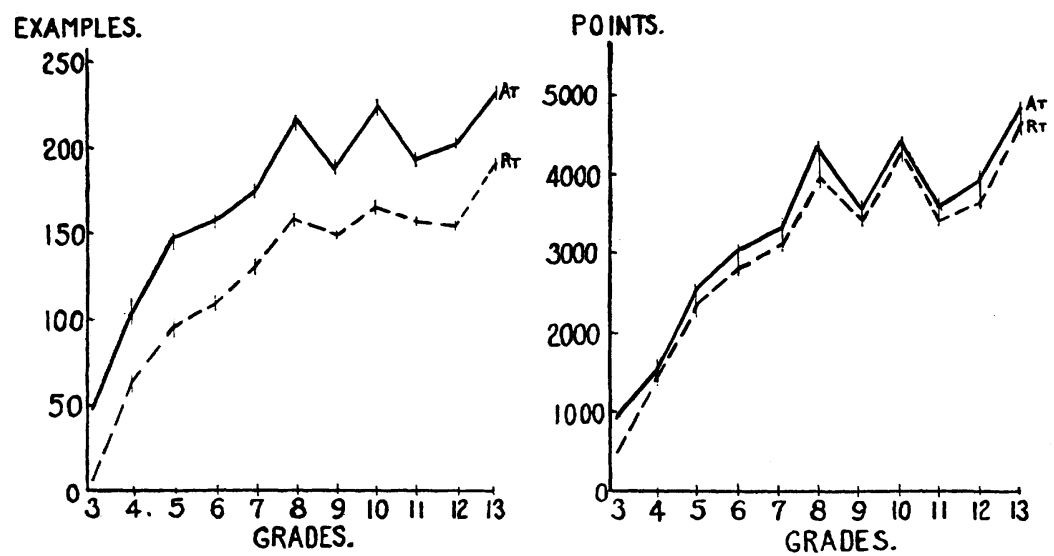

Plot I.-Grade abilities in fundamentals as shown by scores in examples and points, Table I, Part 2.
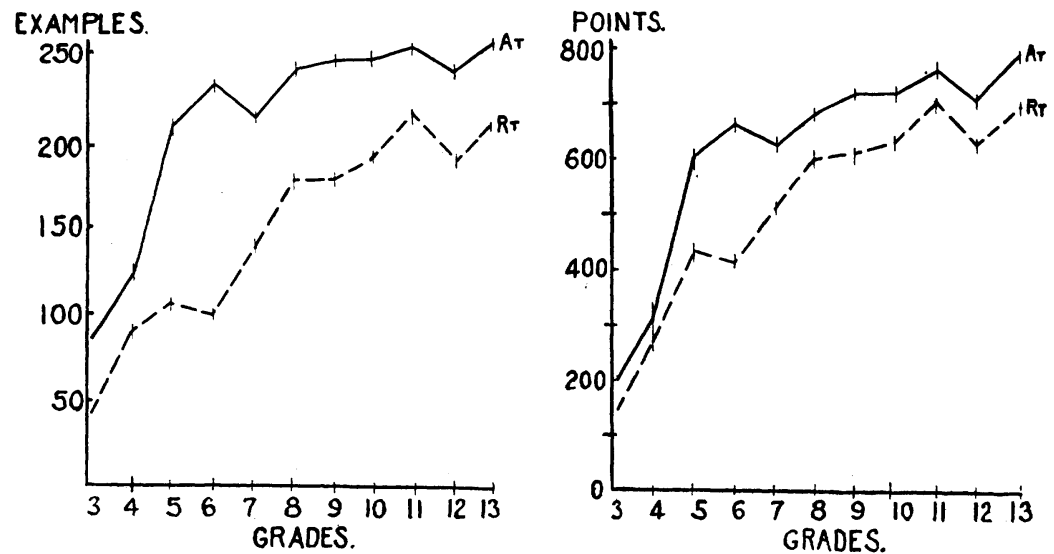

Plot 2.-Grade abilities in reasoning as shown by scores in examples and points, Table I, Part 2.

furnish at best merely a working hypothesis for the planning of the next year's work, which hypothesis must stand or fall by the results of next year's tests. 
Certain facts, however, seem to the writer to stand out plainly. The test in fundamentals appears to have been more difficult than that in reasoning. The latter, in attempts at least, rises to a maximum earlier. Criticism of the test on reasoning will be made later. In the general development of ability there seems to be a rapid and quite uniform rise during the grammar grades and a slight but steady rise during the high-school period. Grade variations in ability make the meaning of the changes in the curve in the upper grades doubtful. It may be that grades 8 and Io are of exceptional ability and the other grades represent the normal results. On the other hand, and this supposition seems the more probable from experience in teaching the various classes, it may be that grades $6,7,9$, I I, and I2 are poor classes, and the true standard curve should follow the crests instead of the troughs of the present curves. Grades 6 and 9 are notoriously poor, grade six because of a peculiar history and grade nine because of poor ideals of work. The real test of the effect of high-school mathematics will come as the results of a good class, as the eighth grade, are successively known through the upper grades. It is to be remembered also that a change of system has been taking place, and that grades II, I2, and I3 may mark the highest achievements under the old régime. For the present it is a pleasure to know that the eighth grade, which has been given a large amount of the new training, is at least not below the standard of any class except the seniors, and it may not be out of place to call attention to the fact that if high-school mathematics does add to ability in arithmetic, the present eighth grade ought to set a new senior record by the time it has finished its course.

It is to be noted that the curves of ability by examples and by points are of the same general character, differing mainly in the degree of accuracy shown. Such differences are due to the character of the mistakes as explained under the discussion of scoring. Hereafter, plots will show either one set of scores or the other unless there is marked difference between them.

The inaccuracy of grades 5 and 6 in the reasoning test needs explanation. These two grades work with fractions and attempted every example containing the fractional idea. It can 
be seen from the test, however, that some of the problems dealt with the principles of partition, about which these classes have learned nothing. Nevertheless, that the sixth grade should succeed in solving less problems than the fifth grade shows the necessity for special and vigorous training if the class as a whole is ever to come up to the standards of the other classes. Yet here again who can say that the factors which have contributed to this result may not operate at a later period to give increased ability?

In comparing the curves for fundamentals with those for reasoning, it will be noted that some classes are high in both, or low in both, while others are high in one and low in the other. This corresponds to classroom experience. The child that can reason well but is poor in abstract work usually passes with the child that is perfect in abstract work and poor in reasoning. This suggests that the truest measure of the abilities of the grades would be a combination score from both tests. It is manifestly unfair to combine 4,820 points in fundamentals with 79I points in reasoning, the achievements of the thirteenth-grade class. Accordingly, in Table II, the scores of Table I, Part 2, have been

\section{TABLE II}

PART I. Comparison scores of Table I, Part 2, adjusted to equality of achievement in fundamentals and reasoning. Thirteenth-grade attempts in both tests called $25^{\circ}$ in examples, and 5,000 in points. Other scores given proportionate values.

PART 2. Total achievements of the grades. Sum of $F$ and $R$ scores Part I for each grade.

\begin{tabular}{|c|c|c|c|c|c|c|c|c|c|c|c|c|}
\hline \multirow{2}{*}{ Grade } & \multicolumn{4}{|c|}{ FundaMENTALS } & \multicolumn{4}{|c|}{ Reasoning } & \multicolumn{4}{|c|}{ TOtal SCORES } \\
\hline & \multicolumn{2}{|c|}{ Examples } & \multicolumn{2}{|c|}{ Points } & \multicolumn{2}{|c|}{ Examples } & \multicolumn{2}{|c|}{ Points } & \multicolumn{2}{|c|}{ Examples } & \multicolumn{2}{|c|}{ Points } \\
\hline & $\begin{array}{l}\text { At } \\
5 \mathrm{I}\end{array}$ & ${ }^{\mathrm{Rt}}{ }_{6}$ & $\begin{array}{l}\text { At } \\
95^{2}\end{array}$ & $\begin{array}{l}\mathrm{Rt} \\
5 \circ 8\end{array}$ & $\begin{array}{c}\text { At } \\
82\end{array}$ & $\begin{array}{l}\mathrm{Rt} \\
40\end{array}$ & $\begin{array}{c}\text { At } \\
\text { I } 277\end{array}$ & $\begin{array}{l}\text { Rt } \\
934\end{array}$ & $\begin{array}{l}\text { At } \\
\text { I33 }\end{array}$ & $\begin{array}{c}\text { Rt } \\
{ }_{46}\end{array}$ & $\begin{array}{l}\text { At } \\
2229\end{array}$ & $\begin{array}{c}\text { Rt } \\
\text { I } 442\end{array}$ \\
\hline 4 . & I I I & 67 & 1628 & I 443 & I $2 \mathrm{I}$ & 85 & 2003 & I 726 & 232 & I 52 & 3631 & 3169 \\
\hline & 160 & IOI & 2682 & 2482 & 204 & IO3 & 3874 & 2761 & 364 & 204 & 6556 & 5223 \\
\hline & I7 I & I I9 & $3 \mathrm{I} 77$ & 2930 & 224 & 96 & 4248 & 2654 & 395 & 2 I 5 & 7425 & $55^{84}$ \\
\hline & I88 & 142 & 3463 & 3267 & 207 & 136 & 4000 & 3280 & 395 & 278 & 7463 & 6547 \\
\hline 8 & 234 & I 72 & 4487 & $4 \mathrm{I} 3 \mathrm{I}$ & 233 & I7 I & $43^{6 I}$ & $3^{8 I I}$ & 467 & 343 & 8848 & 7942 \\
\hline 9 . & 205 & I62 & 3703 & $35^{68}$ & 237 & 172 & $455^{\circ}$ & 3855 & 443 & 334 & 8253 & 7423 \\
\hline Io. & 244 & I79 & 4593 & 4403 & 237 & 182 & $455^{\circ}$ & 4025 & $47 \mathrm{I}$ & $36 I$ & 9I43 & 8428 \\
\hline I I. & 209 & I 70 & 3739 & 3568 & 245 & 209 & 4854 & 4487 & 454 & 379 & 8593 & 8055 \\
\hline I 2. & 217 & I68 & $405 \mathrm{I}$ & 3819 & 230 & I84 & 4500 & 4019 & 447 & $35^{2}$ & $855^{\mathrm{I}}$ & 7838 \\
\hline I $3 \ldots$ & $25^{\circ}$ & 207 & 5000 & 4856 & $25^{\circ}$ & 203 & 5000 & 4424 & 500 & 410 & 10000 & 9280 \\
\hline
\end{tabular}


equalized by calling the thirteenth-grade achievements in both fundamentals and reasoning an arbitrary equal value and recomputing the other scores to correspond. The values chosen were
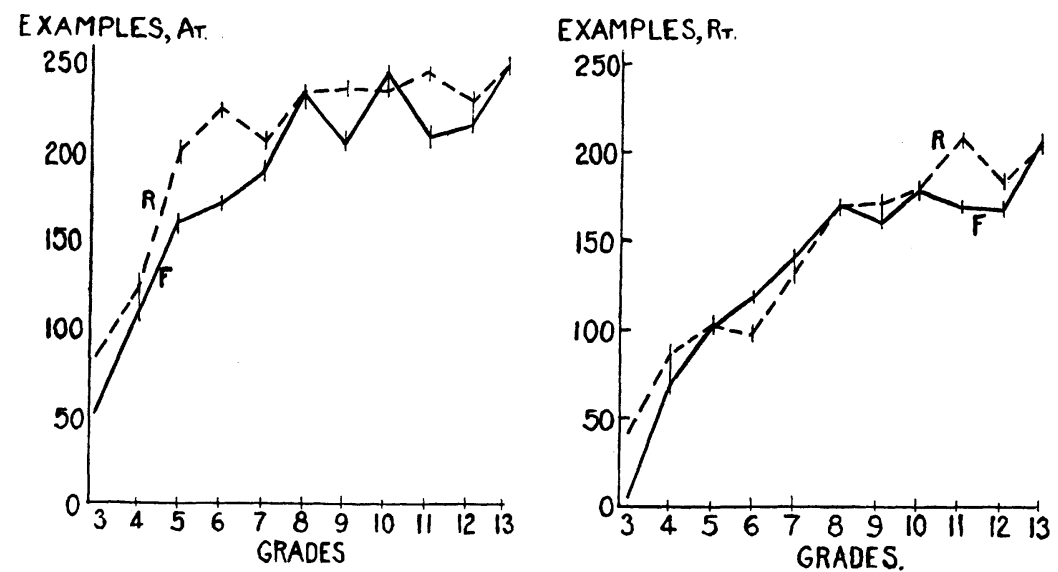

Plot 3.-Comparison of achievements in fundamentals and reasoning by examples. Scores recomputed and equalized on a basis of 250 for the $\mathrm{r}^{\text {th }}$ grade attempts. Full lines show fundamentals; dotted lines show reasoning.

POINTS,AT.

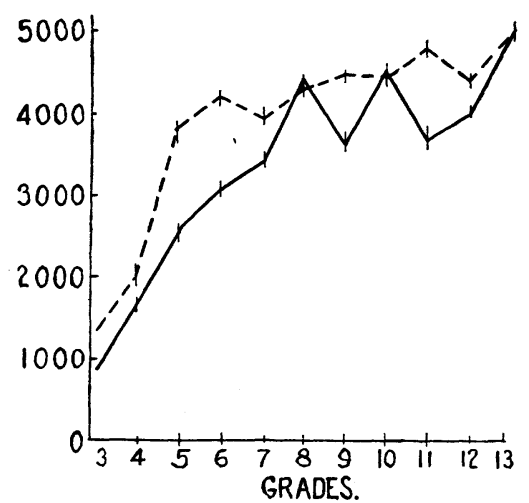

POINTS, RT.

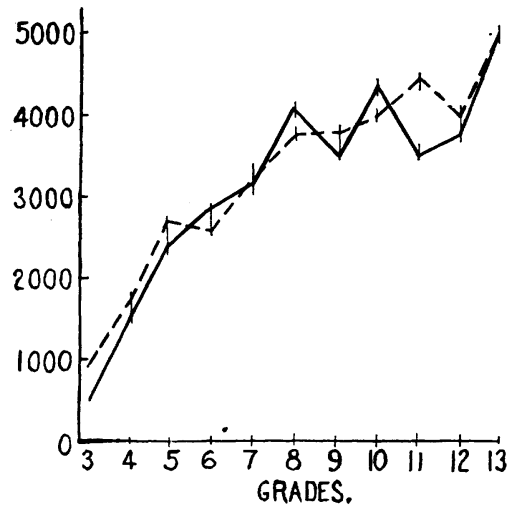

PLOT 4.-Comparison of achievements in fundamentals and reasoning by points. Score recomputed and equalized on the basis of 5,000 for $13^{\text {th }}$ grade attempts. Full lines show fundamentals; dotted lines show reasoning.

250 for examples, and 5,000 for points. Plots 3 and 4 show the relations between the equalized scores graphically. The combined scores are also given and are shown graphically in Plot 5 . 
Plots 3 and 4 make very plain the different types of ability. Grade $\mathrm{I} 2$ is seen to be comparatively poor in both tests, grades 9 and I I good in one and poor in the other, grade 8 good in both. It is certainly a significant fact that grades 5,8 , Io, and I3, taken as representing the normal abilities, should have equal ability in the two tests.

The characteristics of the different grades and the general trend of the development is at once apparent from the curves
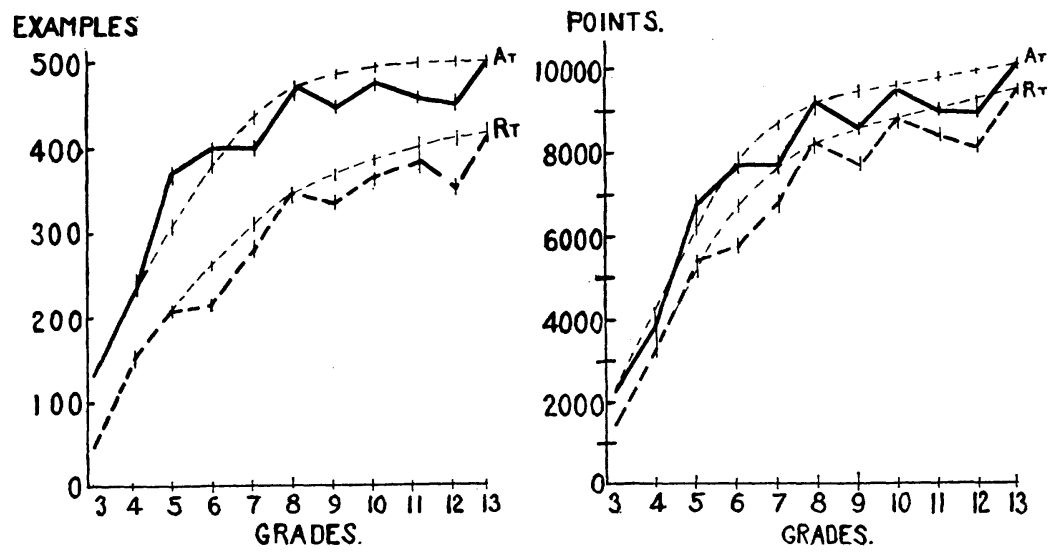

Plot 5.-Total ability as shown by combination of equalized scores. Light dotted curves show probable normal product of present conditions.

obtained from the combination scores, Plot 5 . It will be noted that grades 5, 6, and I2 are inaccurate; grades 7,9 , and II somewhat below normal in ability. The combination scores have evidently made less the marked variations in ability present in the scores for either test alone. The meaning of this is not apparent to the writer. It has been a puzzling fact of his teaching experience that ability to reason and ability to be exact in abstract work seldom go together. He is inclined to believe that there is a psychological principle at work, which, if known, would solve more riddles than one in educational procedure. Whatever the explanation, statistical proof of the fact is given here.

On Plot 5 are drawn in light dotted lines the curves that will be taken as representing the normal product of the training 
given in the school at present (I909). These will serve as standards from which to judge of the effects in changes and methods in the years to come. There are slight differences in form between the curves by examples and those by points, but the most noticeable feature of the plot is the change in accuracy. Accuracy gradually decreases through the grammar grades and increases through the high-school grades at about the same rate. If this result is confirmed by future tests, there is an important lesson here. If inaccuracy in grades 7,8 , and 9 , is due to some natural cause outside of arithmetic proper, to insist on accuracy or to spend much time in working for it may be not only wasteful, but harmful. These curves not only furnish a standard of accuracy for the different grades but a measure of the effect of accuracy as well. For instance, in the thirteenth grade, being able to perform correctly 93 out of a hundred operations (as $3 \times 4$, $8-5)$, means an efficiency of 83 per cent. in working examples like those in the test.

[To be continued] 